\title{
Population-Level Approaches to Universal Health Coverage in Resource-Poor Settings: Lessons from Tobacco Control Policy in Vietnam
}

\author{
Hideki Higashi MPH MSc, Tuan A. Khuong MD PhD, Anh D. Ngo MD MIPH MPhil PhD, Peter S. Hill MBBS PhD
}

\begin{abstract}
Population-based health promotion and disease prevention approaches are essential elements in achieving universal health coverage; yet they frequently do not appear on national policy agendas. This paper suggests that resource-poor countries should take greater advantage of such approaches to reach all segments of the population to positively affect health outcomes and equity, especially considering the epidemic of chronic noncommunicable diseases and associated modifiable risk factors. Tobacco control policy development and implementation in Vietnam provides a case study to discuss opportunities and challenges associated with such strategies.
\end{abstract}

KEYWORDS Health promotion, health policy, smoking, tobacco, developing countries, population-based planning, Vietnam

\section{UNIVERSAL COVERAGE: \\ DEFINITION, ACHIEVEMENTS AND GAPS}

WHO defines universal health coverage as a mechanism where "everyone in the population has access to appropriate promotive, preventive, curative and rehabilitative health care when they need it and at an affordable cost."[1] Despite this broad definition, policy discussions at global and national levels have focused primarily on equitable access to clinical services provided and on financial risk protection,[2] particularly the need for effective health financing mechanisms. For example, in the $58^{\text {th }}$ World Health Assembly (WHA) in 2005, member states adopted resolution WHA 58/33 encouraging governments to develop sustainable health financing mechanisms to achieve or maintain universal coverage in terms of provision of health services.[3]

Universal coverage in health care-as determined solely by financing mechanisms and access to healthcare serviceshas been achieved in 27 member states of the Organization for Economic Cooperation and Development (OECD).[4] Encouraging progress has also been made in some lowand middle-income countries, including Thailand, Sri Lanka, Rwanda, Cuba, Colombia and Chile.[5] Nonetheless, it is without question that universal coverage remains a hard-toreach goal for the majority of developing countries due to lack of resources, over-reliance on direct out-of-pocket payment for health services, and inefficient and inequitable use of available resources.[5]

Health systems worldwide face projected changes in global disease patterns, with a major shift from communicable to chronic non-communicable diseases.[6] Global reduction in mortality from communicable diseases has resulted in an increase in average population age and in the number and proportion of those in the older age brackets more affected by non-communicable diseases.[7] Many of these conditions are of a chronic nature, requiring continuous care at both community and facility levels. This implies extended hospital stays, more expensive medical technologies, and long-term medication regimens that change and increase resource use for health services.

Such a shift to treating chronic non-communicable diseases is easier said than done in developing countries with limited resources. In contrast to expensive treatments, population-based preventive and promotive approaches that address various risk factors for chronic conditions not only have the potential to broadly improve health outcomes, but also are less resource-intensive, providing more feasible options. A small reduction in exposure to risk factors, including tobacco, alcohol, unhealthy diet, or physical inactivity, can lead to population-level lowering of cholesterol, blood pressure and other risk markers for chronic non-communicable diseases.[8]

This approach may be a reasonable alternative if a major risk factor exists that has substantial impact on the leading causes of illness and death. However, identifying such epidemiological profiles is not often straightforward in resource-poor countries due to lack of human resource capacities and comprehensive health information systems. Where possible, nevertheless, epidemiological modelling approaches, such as burden of disease and risk factor analysis, have proven useful. This is the case of studies carried out in both Thailand and Vietnam, among other developing countries. $[9,10]$

In this paper, we argue that, if governments in resource-poor settings are to make tangible progress in health outcomes and equity, policy discussions of universal health coverage should incorporate a broader perspective. Specifically, this must include preventive and promotive approaches at population level, not simply financing mechanisms and access to clinical services. In the following sections, we first provide some examples of population-based approaches that are efficient and do not require major investments. We then take the case of tobacco control policy in Vietnam to explore opportunities and constraints associated with such approaches, discussing implications for other developing countries.

\section{POPULATION-LEVEL PREVENTIVE AND PROMOTIVE APPROACHES}

Population-level approaches aiming to reduce specific risks to health can be implemented without major investments. Most do not limit access to interventions based on financial constraints or access to health facilities, although some segments of the population may benefit more than others, depending on degree of exposure to each risk factor. Unlike individual approaches (e.g., statins for lowering cholesterol, pharmacotherapy for smoking cessation), many population-level preventive approaches have 
potential to cover virtually the entire population, and some even reach more marginalized segments most effectively. Here, we suggest some options for achieving universal health coverage through addressing the promotive and preventive aspects of its definition.

Broadly, there are two strategies for population-level promotive and preventive interventions aimed at influencing behaviors related to risk factors: personal choice and policy enforced. The latter include laws and regulations, while mass media campaigns and other health education activities fall into the former category. Tax and price measures have both characteristics in that they are policy enforced in nature yet their effects on behaviors are dependent on personal choice, hence may constitute a third category, "policy influenced."

Laws and regulations These have significantly contributed to population health in various ways.[11] Examples include legislation banning smoking from specific areas, restrictions on advertising alcohol, compulsory use of seat belts and helmets, and regulation of food ingredients such as salt. Once laws are in place, the resources for implementation are primarily those required for monitoring and enforcement, and are not as costly as individual approaches: for example, estimated annual monitoring and enforcement costs for a public smoking ban are less than $1 \%$ of those for anti-depressant therapy for smoking cessation support per year in Vietnam.[12,13] If compliance is reasonable and adequate enforcement mechanisms are in place, such policies can reach virtually all the population in a given jurisdiction.

Tax and price measures Excise tax has been widely used as a policy instrument to control tobacco and alcohol consumption. Subsidies can also be used to promote better diet by reducing shelf prices to consumers of healthier foods.[8] Once a tax policy is in place, operational costs are limited to those for collection, which, in countries where a well-functioning system exists, adds little to government budgets. We would argue that even in countries without an efficient tax collection system, it may still be a feasible option if the industry is largely stateowned and operates within the government system, as is the case in Vietnam.

Generally, disadvantaged groups are more responsive to price changes than those in higher socioeconomic groups, and in particular, people with lower incomes are more likely to reduce consumption of a commodity when its price increases. It has been shown that smokers in low- and middle-income countries are more sensitive to price changes than those in high-income countries.[14] Therefore, although tax and price measures reach all population segments, marginalized groups potentially gain more health benefits than those who are better off by differentially reducing tobacco use (although they may also increase the proportion of their income spent on tobacco products).

Public awareness campaigns These can include use of television, radio, magazines, billboards, leaflets, and web sites. However, potential for universal reach varies depending on available instruments. Urban residents and those in higher socioeconomic strata would likely have access to most media, while marginalized groups, particularly in rural areas, may have only limited access. In order for these interventions to reach all population segments, special attention must be paid to the selection of dissemination tools.

Cost effectiveness and implications All three approaches described above have potential to provide specific promotive and preventive attention to the entire population served by a national public health system. The WHO Choosing Interventions that are Cost-Effective project (WHO-CHOICE)[15] assessed cost effectiveness of these approaches in 14 epidemiological sub-regions. Overall, all three approaches mentioned above appear to be cost effective in low- and middle-income countries, including excise tax on tobacco and alcohol,[16,17] advertising bans on tobacco products,[16] law-enforced reduction of salt in foods,[18] and health education through mass media. [18] Further, the absolute cost of implementation appears to be substantially lower than that targeting individuals. $[16,18]$

\section{IMPLEMENTATION CHALENGES}

However, the lower investment required for such interventions does not necessarily imply easy implementation. The general political and socioeconomic contexts, as well as system-wide public administration capacities, must be considered when determining appropriate strategies. Macroeconomic development is often positioned higher on the policy agenda than social equity issues such as health and education, and hence, economic decisions must be monitored and successfully challenged when necessary. This also implies that multidisciplinary evidence, including health and socioeconomic implications, must be communicated effectively to decision-makers so that they can appreciate overall benefit to society.

Decision-makers typically
find it challenging to balance
socioeconomic implications
and population health
enhancement.

Behavioral change strategies based on personal choice depend on increased awareness of risk factors or policy influences (i.e. tax and price changes) that may or may not lead to healthier decisions of the population. However, this approach assumes that healthier alternatives are widely available and affordable, and that risk-factor education is relatively easy to implement.[19] This assumption may not always hold in countries where few alternatives are available and literacy rates low.

Apart from limitations associated with administrative and legal systems, which vary among countries, many promotive and preventive approaches at population level interact with trade and industry sectors, such as tobacco, alcohol and food industries, that can constrain implementation (e.g. exemption of certain products from excise taxes). Decision-makers typically find it challenging to balance socioeconomic implications and population health enhancement. They often encounter interference from lobbyists and rivalry from different government sectors trying to protect or enhance their own agendas, fearing these might be compromised by decisions supporting improved population health. In the following section, we use the case of tobacco control policy in Vietnam to discuss how the government has taken promotive and preventive approaches to reach the entire population and how different stakeholders involved have influenced the policy process. 


\section{TOBACCO CONTROL POUCY IN VIETNAM}

Vietnam is a developing country in Southeast Asia. Since the inception of the Doi Moi (renovation) policy in 1986, the country has achieved substantial socioeconomic development. In health, half the population is now covered by some kind of health insurance scheme.[20] However, universal coverage is still a long way off, particularly for those in the informal sector (i.e. unregistered private enterprises that produce some of their goods and services for sale or barter, and are engaged in non-agricultural activities).[21]

In this context, the Ministry of Health $(\mathrm{MOH})$ has tackled a major risk factor poised to cause an explosion of the non-communicable disease burden in the future: smoking. Vietnam has one of the highest smoking rates in the world; fully half the adult male population smokes.[22] The tobacco industry is mostly state owned, and three foreign brands (Phillip Morris, British American Tobacco and Japan Tobacco) are manufactured locally by state companies under licensing agreements.

To address the smoking epidemic, the government adopted the National Tobacco Control Policy (NTCP) 2000-2010 resolution. [23] Various broad interventions have since been implemented with some success, including excise tax, advertising bans, package label health warnings, and others.[24] During the policy process, Vietnam signed the Framework Convention on Tobacco Control (FCTC) in 2003, one of the first countries in the region to do so.[25] FCTC commits countries to take action to control the smoking epidemic and suggests a variety of interventions. In 2009, the Vietnamese government drew up an action plan for FCTC implementation largely following the principles contained in the Convention.[26]

In order to strengthen the legal foundations of various tobacco control interventions, the Tobacco Harm Prevention Law (THPL) is being drafted by the $\mathrm{MOH}$ for introduction to the parliament in 2011.

To build the evidence base for THPL, the cost effectiveness of ten tobacco control interventions was investigated.[12,13] Cost effectiveness was expressed as intervention costs per disabilityadjusted life year (DALY) gained, and health gain was defined by reduction of smoking prevalence through the interventions investigated. It was shown that population-level interventions-including excise tax increases, pictorial package warning labels, mass media campaigns, and legislation mandating smoke-free areaswere all quite cost effective.

On the other hand, personal smoking cessation supports were generally not cost effective, particularly pharmacological therapies, such as nicotine replacements, anti-depressants, and nicotine-receptor partial agonists. The only exception was physician advice, although its cost effectiveness was not as great as that of population-level approaches and it did not reach the entire population. These findings are not surprising if we consider the generally less extensive healthcare coverage and lower ability to pay for medications in Vietnam compared to more affluent countries.

Despite the favorable cost effectiveness of population-level approaches and some implementation success to date, stakeholder perceptions investigated by several methods- key informant interviews, a focus-group discussion and survey questionnaires-are somewhat mixed. Key stakeholders included in the study were the national ministries of health, finance, and trade and industry; parliament office and members; Government Office; the Communist Party of Vietnam; non-governmental organizations, and WHO. Interventions viewed positively by a majority of tobacco-control policy stakeholders include mass media campaigns and personal smoking cessation support; while excise tax and pictorial warning labels received the least support.[26] Smoking bans have general support, although the Ministry of Trade and Industry (MTI), which oversees the entire tobacco industry-including joint ventures with foreign tobacco companies-does not support a complete ban.[27]

Excise tax, which reaches virtually all cigarette smokers, has met a degree of resistance from $\mathrm{MTI}$, the Ministry of Finance (MOF) and some members of the National Assembly. Opponents often cite concerns that these interventions could increase smuggling and unemployment, as well as reduce government revenue.[27]

Although there is insufficient evidence to support such claims worldwide, they tend to influence policy-makers, negatively affecting their positions on population-level approaches. National Assembly members' reluctance to support tax increases is largely due to economic implications.[27] This concern also influences tobacco control advocates: in general, since they are well aware of what might or might not be acceptable to the most stakeholders, they sometimes modify their positions accordingly, effectively self-censoring.[27]

Stakeholder reluctance, particularly on the part of MTI and MOF, has slowed the legislative process for THPL, deferring its consideration by the National Assembly one year from the original date in 2010. Further complicating the situation is the fact that, despite draft legislation already in process led by $\mathrm{MOH}$, MTI is preparing a parallel tobacco law focusing on tobacco production and consumption, with the intention of subsuming THPL and appropriating the lead role in tobacco control.[27] THPL may be completely different from what has been discussed and drafted thus far-and more effective tobacco control policies either advanced or stalled-depending on which ministry assumes leadership.

\section{CONCLUSIONS}

Population-level promotive and preventive approaches have potential to reach even the most marginalized strata of the population. The case of tobacco control policy in Vietnam has demonstrated that population-based interventions could achieve substantial health improvement at reasonably low cost even in resource-poor settings.

However, it has also shown that such interventions are not easily implemented due to political challenges exerted by stakeholders with competing agendas. Nonetheless, for many low- and middleincome countries, it is a vital alternative to the traditional discussion of universal coverage that focuses on financing schemes. Thus, we recommend that policy discussions on universal coverage at national and global levels incorporate a broader perspective, including population-level promotive and preventive approaches. $-1 / 2$ 


\section{REFERENCES}

1. Carrin G, James C, Evans D. Achieving universal health coverage: developing the health financing system. Geneva: World Health Organization; 2005.

2. WHO. Closing the gap in a generation: health equity through action on the social determinants of health. Final Report of the Commission on Social Determinants of Health. Geneva: World Health Organization; 2008.

3. WHO. Sustainable health financing, universa coverage and social health insurance. Geneva World Health Organization; 2005.

4. OECD. Health at a glance 2009: OECD indicator. Paris: Organization for Economic Co-operation and Development; 2009.

5. WHO. The World Health Report - health systems financing: the path to universal coverage. Geneva: World Health Organization; 2010.

6. WHO. World Health Statistics 2008. Geneva: World Health Organization; 2008.

7. Gottret P, Schieber G. Health financing revisited: a practitioner's guide. Washington D.C.: World Bank Publications; 2006. 336 p.

8. WHO. Preventing chronic diseases: a vital investment. Geneva: World Health Organization; 2005.

9. Bundhamchareon K, Teerawattananon Y, Vos T, Begg S. Burden of Disease and Injuries in Thailand. Nonthaburi, Thailand. Ministry of Public Health. Nonthaburi (TH): Bureau of Health Policy and Planning, Ministry of Public Health (TH); 2002.

10. Vietnam Evidence for Health Policy (VINE) Project. Vietnam burden of disease and injury study 2008. Brisbane and Hanoi: School of Population Health, The University of Queensland, Hano School of Public Health, Ministry of Health (VN) 2011.

11. Goodman RA, Hoffman RE, Lopez W, Matthews GW, Rothstein MA, Foster KL, editors. Law in public health practice. 2nd ed. New York: Oxford University Press, USA; 2006 Nov 23. 608 p.

12. Higashi $\mathrm{H}$, Truong KD, Barendregt JJ, Nguyen PK, Vuong ML, Nguyen TT, et al. Cost Effectiveness of Tobacco Control Policies in Vietnam: The Case of Population-Level Interventions. App Health Econ Health Policy. 2011 May 1;9(3):18396.

13. Higashi $\mathrm{H}$; the Tobacco Cost-Effectiveness Com ponent (VINE Project). Cost-effectiveness of tobacco control policy in Vietnam: population vs. individual approaches. 5th Emerging Health Policy
Research Conference; 2010 Aug 11. Sydney: Menzies Centre for Health Policy; 2010.

14. Ross H, Chaloupka FJ. Economic policies for tobacco control in developing countries. Salud Pública Mex. 2006;48 Suppl 1:S113-20.

15. WHO. CHOosing Interventions that are Cost Effective (WHO-CHOICE) [Internet]. Geneva: World Health Organization; 2011[cited 2011 Jan 16]. Available from: http://www.who.int/choice/en/

16. Shibuya K, Ciecierski C, Guindon E, Bettcher DW, Evans DB, Murray CJ. WHO Framework Convention on Tobacco Control: development of an evidence based global public health treaty. BMJ. 2003 Jul 19;327(7407):154-7.

17. Chisholm D, Rehm J, Van Ommeren M, Monteiro M. Reducing the Global Burden of Hazardous Alcohol Use: A Comparative Cost-Effectiveness Analysis. J Stud Alcohol. 2004 Nov;65(6):78293.

18. Murray CJ, Lauer JA, Hutubessy RC, Niessen L, Tomijima N, Rodgers A, et al. Effectiveness and costs of interventions to lower systolic blood pressure and cholesterol: a global and regional analysis on reduction of cardiovascular-disease risk. Lancet. 2003 Mar 1;361(9359):717-25.

19. Reddy KS. Cardiovascular Disease in NonWestern Countries. N Engl J Med. 2004 Jun 10;350(24):2438-40.

20. Ekman B, Liem NT, Duc HA, Axelson H. Health insurance reform in Vietnam: a review of recent developments and future challenges. Health Policy Plan. 2008;23(4):252-63.

21. Cling JP, Nguyen TTH, Nguyen HC, Tram PTN, Razafindrakoto M, Roubaud F. The Informal Sector in Vietnam: A focus on Hanoi and Ho Chi Minh City. Hanoi: The Gioi Editions; 2010. 190 p.

22. GSO. Result of the Vietnam household living standards survey 2006. Hanoi: General Statistics Office (VN); 2007.

23. Government of Vietnam. National tobacco control policy 2000-2010. Hanoi: Government of Vietnam; 2000

24. SEATCA. Status of tobacco use and its control: Vietnam report card. Bangkok: Southeast Asia Tobacco Control Alliance; 2008.

25. WHO. Framework Convention on Tobacco Control. Geneva: World Health Organization; 2003.

26. Government of Vietnam. On the ratificaton of the plan for the implementation of the Framework Convention on Tobacco Control. Vietnam; 2009
27. Higashi H, Khuong T, Ngo A, Barendregt JJ, Hill P. Population-level approaches to achieve universal public health: the role of evidence and politics involved in the tobacco control policy in Vietnam. 1st Global Symposium on Health Systems Research; 2010 Nov 16-19; Montreaux, Switzerland

\section{THE AUTHORS}

Hideki Higashi (Corresponding author: h.higashi@uqconnect.edu.au), health economist and research fellow, School of Population Health, University of Queensland, Brisbane, Australia.

Tuan A. Khuong, physician with advanced degrees in public health. Researcher (health systems), Department of Health Services Management and Provision, Health Strategy and Policy Institute, Hanoi, Vietnam.

Anh D. Ngo, physician specializing in epidemiology, with master's degrees in international public health and epidemiology and a doctorate in public health. Research fellow, School of Population Health, University of Queensland, Vietnam Evidence for Health Policy Project, Hanoi, Vietnam.

Peter S. Hill, public health physician with diplomas in tropical medicine and hygiene and obstetrics, and a doctorate in medical science. Associate Professor (global health systems), School of Population Health, University of Queensland, Brisbane, Australia.

Submitted: February 11, 2011

Approved for publication: June 8, 2011

Disclosures: None 